\title{
HUBUNGAN KUALITAS TIDUR DENGAN PENINGKATAN TEKANAN DARAH PADA LANSIA
}

\author{
Relationship Of Sleep Quality With Increased Blood Preessure In The Elderly
}

\author{
Kurniadi I' \\ *STIKes EKA HARAP, Palangka \\ Raya, Kalimantan Tengah, \\ Indonesia
}

*email:

Kurniadil405@Gmail.com

\begin{abstract}
Abstrak
Latar Belakang : Pada umummya semakin bertambahnya usia maka semakin besar pula risiko terjadinya hipertensi. Fenomena yang didapatkan banyak pasien lansia penderita hipertensi mengeluh sulit tidur, sering terbangun dimalam hari sehingga berdampak pada tekanan darah yang disertai dengan keluhan pusing dan lemas saat bangun tidur dipagi harinya.

Tujuan Penelitian : Penelitian ini bertujuan untuk mengatahui "Hubungan Kualitas Dengan Peningkatan Tekanan Darah Pada Lansia”.

Metode Penelitian : Metode penelitian ini menggunakan metode Literature Review. pada penelitian ini terdapat 6 jurnal yang sudah di Screening dengan kriteria inklusi mulai dari sample 22-107 responden, dengan I studi design yaitu cross sectional, tahun terbit jurnal 2017-2020 dan menggunakan Bahasa Indonesia.

Hasil : Diperoleh 6 hasil penelitian sesuai kriteria inklusi. Sampel penelitian ratarata 22-107 responden, bahwa dimana hasil penelitian 6 jurnal terdapat kesesuaian yang menunjukan bahwa ada hubungan kualitas tidur dengan peningkatan tekanan darah pada lansia yang menunjukan nilai $p$ value $<0,05$.

Kesimpulan : Kualitas tidur yang buruk dapat mempengaruhi dan memudahkan lansia mengalami peningkatan tekanan darah, diharapkan untuk lansia dapat mencegah terjadinya hipertensi dengan cara rutin pemeriksaan tekanan darah, pengobatan secara rutin, dan menjalani pola hidup yang sehat, seperti menghindari pola asupan garam yang tinggi, olah raga dan untuk mencegah gangguan tidur yang berkelanjutan lansia dapat mengatur jadwal tidurnya dengan baik.
\end{abstract}

\begin{abstract}
Background: In general, the older you get, the greater the risk of hypertension. The phenomenon obtained by many elderly patients with hypertension complains of difficulty sleeping, often wakes up at night so that it has an impact on blood pressure accompanied by complaints of dizziness and weakness when waking up in the morning.

Research Objectives: This study aims to determine the "Relationship of Sleep Quality

With Increased Blood Pressure in the Elderly".

Research Methods: This research method uses themethod Literature Review. In this study, there are 6 journals that have been screened withcriteria inclusion ranging from a sample of 22-107 respondents, with I study design, namely cross sectional, journal published in 2017-2020 and using Indonesian.

Results: Obtained 6 research results according to the inclusion criteria. The research sample averaged 22-107 respondents, that where the results of the research in 6 journals were in agreement, which showed that there was a relationship between sleep quality and increased blood pressure in the elderly, which showed a $p$ value $<0.05$.

Conclusion: Poor sleep quality can affect and make it easier for the elderly to experience increased blood pressure, it is hoped that the elderly can prevent hypertension by routinely checking blood pressure, routine treatment, and living a healthy lifestyle, such as avoiding high salt intake patterns, exercising. exercise and to prevent ongoing sleep disturbances the elderly can manage their sleep schedule well.
\end{abstract}

(C) year The Authors. Published by Institute for Research and Community Services Universitas Muhammadiyah Palangkaraya. This is Open Access article under the CC-BY-SA License (http://creativecommons.org/licenses/by-sa/4.0/). DOI: https://doi.org//0.33084/jsm.vxix.xxx.

\section{PENDAHULUAN}

Kualitas tidur yang tidak baik akan memudahkan lansia mengalami kekambuhan penyakit hipertensi, karena kualitas tidur yang buruk dapat mengubah hormon stress kontisol dan system saraf simpatik, sehingga terjadi peningkatan tekanan darah (Amanda et al., 2017). Hal tersebut disebabkan oleh perubahan struktur pembuluh darah seperti penyempitan lumen, 
serta dinding pembuluh darah menjadi kaku dan elastisitasnya berkurang sehingga meningkatkan tekanan darah (Adam, 2019). Fenomena yang didapatkan di UPT Puskesmas Kalampangan saat melakukan rujukan, banyak pasien lansia penderita hipertensi mengeluh sulit tidur, sering terbangun dimalam hari sehingga berdampak pada tekanan darah yang disertai dengan keluhan pusing dan lemas saat bangun tidur dipagi harinya.

Menurut penelitian (WHO tahun 2019), hipertensi merupakan penyakit tidak menular yang menjadi salah satu penyebab kematian prematur di dunia, World Health Organization (WHO) mengestimasikan saat ini prevalensi hipertensi secara global sebesar 22\% dari total penduduk dunia. Dari seperlima yang melakukan upaya pengendalian terhadap tekanan darah yang dimiliki. Wilayah Afrika memiliki prevalensi hipertensi tertinggi sebesar 27\%. Asia Tenggara berada pada posisi ke-3 tertinggi dengan prevalensi sebesar $25 \%$ terhadap total penduduk. Pada tahun 2025 diketahui sebuah prognosis yang menyatakan bahwa I,5 Milliar orang akan mengalami resiko hipertensi, yang akibatnya 17 juta orang dibawah usia 70 tahun telah dilaporkan meninggal akibat penyakit tidak menular. Data di Indonesia, berdasarkan hasil Riset Kesehatan Dasar (Riskesdas, 2018), prevalensi hipertensi pada Kalimantan Tengah pada penduduk usia 60> tahun sebesar 64,7l\%. Dengan hasil jumlah prevalensi pengukuran pada penduduk usia 60> tahun sebanyak I4.924 kasus dan menjadi peringkat tertinggi dalam banyaknya kusus hipertensi berdasarkan usia dibawah 60 tahun lainya. Berdasarkan data dari (Profil Dinkes Prov. Kalteng, 2019) dilaporkan penderita hipertensi mencapai 27.639 pada usia 60> tahun dan hanya $57,27 \%$ mendapatkan pelayanan Kesehatan, angka tersebut mengalami peningkatan jika dibandingkan estimasi tahun 2018 mencapai 14.924 pada usia 60> tahun. Berdasarkan data dari (Profil Dinkes Prov. Kalteng, 2020) prevalensi hipertensi pada tingkat Provinsi Kalimantan tengah pada tahun 2020 dengan usia 60> tahun sebanyak 10.567 kasus lama dengan penambahan kasus baru sebanyak I.I24 pertahun. Berdasarkan data ( Profil Puskesmas Kalampangan, 2020) jumlah kasus hipertensi pada tahun 2019 berdasarkan umur $60>$ tahun sebanyak II 3 kasus yang terjadi

Secara umum faktor peningkatan tekanan darah disebabkan oleh berbagai macam masalah yaitu masalah fisik, psikologis, sosial serta dukungan keluarga. Hipertensi juga dapat mengakibatkan munculnya masalah-masalah Kesehatan yang berdampak pada tubuh manusia, serta pada kualitas hidupnya. Hal utama yang dipermasalahkan pada pasien hipertensi ialah kualitas tidur, kualitas tidur merupakan salah satu masalah internal yang paling sering terjadi dan sering dikeluhkan oleh para lansia yang mengalami hipertensi, hal ini dapat terjadi karena terjadinya durasi tidur yang pendek yang dapat menimbulkan kualitas tidur menjadi buruk (Ponda \& Boky, 2017). Kurangnya durasi tidur yang berkepanjangan dapat menggangu Kesehatan fisik dan psikis. Dari segi fisik yaitu kurangnya tidur akan menyebabkan mata sembab, muka pucat, badan lemas dan daya tahan tubuh menurun sehingga mudah terserang penyakit. Sedangkan dari segi psikis yaitu, kurang tidur akan menyebabkan timbulnya perubahan suasana kejiwaan, sehingga penderita akan lesu, lamban menghadapi rangsangan dan sulit berkonsentrasi, kualitas tidur yang tidak cukup dapat mengangggu memori dan kemampuan kognitif, bila hal ini berlanjut hingga bertahun-tahun, akan berdampak pada tekanan darah tinggi, serangan jantung, stroke, hinggga masalah psikologis seperti depresi dan gangguan perasaan lainya. Apabila hal ini berlangsung dalam waktu yang lama, akan menyebabkan individu tersebut mengalami kurang tidur yang mengakibatkan peningkatan resiko penyakit yang dideritannya (Purwati, 2018). Menurut penelitian (Sambeka et al., 2018) dengan meneliti seluruh lansia berumur $>60$ tahun, dengan total sampling yaitu 76 responden, menunjukan bahwa responden yang menderita hipertensi dengan memiliki 
kualitas tidur buruk berjumlah $40(81,6 \%)$ responden dan responden yang tidak menderita hipertensi serta memiliki kualitas tidur baik berjumlah 12 (44,5\%) responden. Responden yang tidak menderita hipertensi dan memiliki kualitas tidur buruk berjumlah $9(18,4 \%)$ responden sedangkan responden yang tidak menderita hipertensi serta memiliki kualitas tidur baik berjumlah 15 (55,5\%) responden. Hasil uji statistic chi square menunjukan bahwa nilai $\mathrm{p}=0,05$ sehingga $\mathrm{H} 0$ ditolak dan dapat dikatakan bahwa terdapat hubungan yang bermakna antara kualitas tidur dengan hipertensi pada lansia. Berdasarkan penelitian dari (Aji, 2016) menjelaskan bahwa adanya hubungan signifikasi antara kualitas tidur dengan hipertensi pada usia lanjut di Posyandu Lansia Dusun Jalapan Sindumartani Ngemplak Sleman. Keeratan hubungan antara kualitas tidur dengan hipertensi pada usia lanjut tersebut bersifat kuat. Kebanyakan responden yang mempunyai kualitas tidur dengan kategori buruk mayoritas memiliki tekanan darah hipertensi sedang. Sedangkan responden yang mempunyai kualitas tidur kategori baik mayoritas memiliki hipertensi ringan. Penelitian juga pernah dilakukan oleh (Alfi, 20I7) menjelaskan bahwa antara kualitas tidur dengan tekanan darah pada pasien hipertensi di wilayah kerja Puskesmas Mojolangu Kota Malang memiliki hubungan yang kuat. Hasil dari penelitian tersebut menunjukan bahwa orang dengan kualitas tidur buruk, lebih rentan untuk mengalami peningkatan tekanan darah pada penderita hipertensi. Dari Penelitian-penelitian tersebut memiliki hasil yang sama yang menjelaskan bahwa semakin bertambahnya usia akan menyebabkan kualitas tidur akan terganggu, dengan terganggunya kualitas tidur lebih rentan untuk mengalami peningkatan tekanan darah.

Bagi tenaga Kesehatan perlunya peningkatan peran serta progam promosi Kesehatan seperti penyuluhan atau pemkes untuk meningkatkan pengatahuan penderita hipertensi tentang penyakit hipertensi agar penderita hipertensi dapat mengatur pola hidupnya sesuai dengan pola hidup sehat. Bagi lansia diharapkan untuk dapat mencegah terjadinya hipertensi dengan cara rutin pemeriksaan tekanan darah, pengobatan secara rutin, dan menjalani pola hidup yang sehat, seperti menghindari pola asupan garam yang tinggi, olah raga dan untuk mencegah gangguan tidur yang berkelanjutan lansia dapat mengatur jadwal tidurnya dengan baik.

\section{METODOLOGI}

Penelitian ini merupakan studi literature review atau tinjauan pustaka yang dimana bahwa dijelaskan literature review adalah analisis terintegrasi tulisan ilmiah yang terkait langsung dengan pertanyaan penelitian (Nursalam, 2020). Studi literature review merupakan studi yang dipakai untuk mengumpulkan data sekunder yang berhubungan atau terkait dengan topik tertentu yang bisa didapatkan dari berbagai sumber seperti buku, jurnal, internet dan pustaka lainnya. Metode penelitian dapat diartikan sebagai cara ilmiah untuk mendapatkan data yang valid dengan tujuan dapat ditemukan, dikembangkan, dan dibuktikan, suatu pengetahuan tertentu sehingga pada gilirannya dapat digunakan untuk memahami, memecahkan dan mengantisipasi masalah (Sugiyono, 2016).

Desain penelitian ini dilakukan dengan pendekatan cross-sectional. Penelitian cross-sectional adalah suatu penelitian untuk mempelajari dinamika korelasi antara faktor-faktor risiko dengan efek, dengan cara pendekatan, observasional, atau pengumpulan data. Penelitian cross-sectional hanya mengobservasi sekali saja dan pengukuran dilakukan terhadap variabel subjek pada saat penelitian (Notoatmojo, 20I0). Judul dalam penelitian ini adalah “ Hubungan Kualitas Tidur Dengan Peningkatan Tekanan Darah Pada Lansia”. Variabel independen "Kualitas Tidur dan variabel dependen “ Tekanan Darah”.

\section{HASIL DAN PEMBAHASAN}


Hasil analisis dari 6 jurnal menujukan lebih dominan responden memiliki kualitas tidur yang buruk sebanyak 266 orang (78\%) dan kualitas tidur yang baik sebanyak 43 orang (22\%) dan tekanan darah menunjukan lebih dominan responden memiliki tekanan darah 120 139/80-89 berjumlah III (58\%) orang ,untuk hipertensi stage I berjumlah 77 orang (20\%), dan untuk hipertensi stage II berjumlah 56 orang (I2\%), tekanan darah yang dikatakan normal 51 orang (10\%). Diperoleh 6 hasil penelitian sesuai kriteria inklusi. Sampel penelitian rata-rata 22-107 responden, bahwa dimana hasil penelitian 6 jurnal terdapat kesesuaian yang menunjukan bahwa ada hubungan kualitas tidur dengan peningkatan tekanan darah pada lansia yang menunjukan nilai $\mathrm{p}$ value $<0,05$.

\section{KESIMPULAN}

Kualitas tidur yang buruk dapat mempengaruhi dan memudahkan lansia mengalami peningkatan tekanan darah, diharapkan untuk lansia dapat mencegah terjadinya hipertensi dengan cara rutin pemeriksaan tekanan darah, pengobatan secara rutin, dan menjalani pola hidup yang sehat, seperti menghindari pola asupan garam yang tinggi, olah raga dan untuk mencegah gangguan tidur yang berkelanjutan lansia dapat mengatur jadwal tidurnya dengan baik..

Saran untuk penelitian selanjutnya:

I. Hasil penelitian ini dapat digunakan sebagai bahan pertimbangan jika suatu saat dilakukan penelitian dan referensi pengembangan ilmu dan teknologi bahan bacaan di perpustakaan digunakan sebagai informasi dan masukan sebagai bahan referensi

Bagi penelitian selanjutnya khususnya dalam ilmu Kesehatan masyarakat diharapkan bisa menjadi acuan atau referensi bagi peneliti selanjutnya dalam melakukan penelitian mengenai hubungan kualitas tidur dangan peningkatan tekanan darah pada lansia sehingga dapat meningkatkan pengatahuan khusunya pada lansia yang masalah kualitas tidur yang buruk.

\section{UCAPAN TERIMA KASIH}

Peneliti mengucapkan terima kasih kepada:

I. Bapak DR. dr. Andryansyah Arifin MPH. selaku Ketua Yayasan Eka Harap Palangka Raya yang telah menyediakan sarana dan prasarana kepada penulis dalam menempuh pendidikan di STIKES Eka Harap Palangka Raya.

2. Ibu Maria Adelheid Ensia, S.Pd., M.Kes. Selaku Ketua STIKES Eka Harap Palangka Raya yang telah menyediakan sarana dan prasarana kepada penulis dan mengikuti pendidikan di STIKES Eka Harap Palangka Raya.

3. Ibu Lensi Natalia Tambunan, SST, M.Kes. selaku Ketua Program Studi Sarjana Kesehatan Masyarakat STIKES Eka Harap Palangka Raya.

4. Ibu Rizki Muji Lestari, SST, M.Kes selaku Ketua Penguji yang telah bersedia meluangkan waktu untuk menguji skripsi ini.

5. Ibu Mariaty A. Sangkai, SPd, M.Kes.selaku Pembimbing I yang telah membantu dan membimbing saya dalam pembuatan skripsi ini, sehingga skripsi ini dapat terselesaikan tepat waktu.

6. Ibu Melisa Frisilia, S.Kep., M.Kes. selaku Pembimbing II yang juga telah membantu saya dalam meyelesaikan skripsi ini dan bersedia membagikan ilmunya dalam membantu saya menyelesaikan skripsi ini.

7. Kepada kedua orang tua saya, terima kasih atas dukungan serta doa yang selalu diberikan kepada saya.

8. Seluruh rekan-rekan dan sahabat saya yang telah banyak membantu dalam menyelesaikan skripsi ini. Semoga bantuan serta budi baik yang telah diberikan kepada peneliti, mendapatkan balasan dari Allah SWT. Besar harapan peneliti agar skripsi ini dapat bermanfaat.

\section{REFERENSI}

I. Amanda, H., Prastiwi, S., \& Sutriningsih, A. (2017). 
Hubungan kualitas tidur dengan tingkat kekambuhan hipertensi pada lansia di kelurahan tlogomas Kota Malang. Nursing News, 2(3), 437447.

https://publikasi.unitri.ac.id/index.php/fikes/article/ view/680

2. Adam, L. (2019). Determinan Hipertensi Pada Lanjut Usia. Jambura Health and Sport Journal, I(2), 82-89. https://doi.org/ 0.373 I I/jhsj.v/i2.2558

3. Kementerian Kesehatan RI. (2018). Laporan Riskesdas 2018. Laporan Nasional Riskesdas 2018, 53(9), I54-165. http://www.yankes.kemkes.go.id/assets/downloads /PMK No. 57 Tahun 2013 tentang PTRM.pdf

4. Dinas Kesehatan Provinsi Kalimantan Tengah. (2020). Profil Kesehatan Kalimantan Tengah. Dinkes Prov. Kalteng.

5. Ponda, A., \& Boky, M. (20I7). Faktor-faktor yang Berhubungan dengan Kejadian Hipertensi pada Masyarakat di Wilayah Kerja Puskesmas Teling Atas Manado. Journal Of Community \& Emergency, 5(3), 5-8.

6. Purwati, Y. (2018). Hubungan Kualitas Tidur dengan Kejadian Hipertensi pada Lansia di Kabupaten Bantul Sleep Quality with Hypertension Incidence in Elderly in Bantul Yenny Purwati I, Probosuseno 2 , Arinto Hadi 3. $1-13$. 